\title{
A systematic review of ultrasound biomicroscopy use in pediatric ophthalmology
}

\author{
Janet L. Alexander $\left(\mathbb{C}^{1} \cdot\right.$ Libby Wei $^{2} \cdot$ Jamie Palmer $^{2} \cdot$ Alex Darras $^{1} \cdot$ Moran R. Levin ${ }^{1} \cdot$ Jesse L. Berry $^{3} \cdot$ \\ Emilie Ludeman ${ }^{4}$
}

Received: 15 August 2020 / Revised: 27 August 2020 / Accepted: 7 September 2020 / Published online: 22 September 2020

(c) The Author(s), under exclusive licence to The Royal College of Ophthalmologists 2020

\begin{abstract}
Ultrasound biomicroscopy (UBM) is the only available option for noninvasive, high-resolution imaging of the intricate iridociliary complex, and for anterior segment imaging with corneal haze or opacity. While these unique features render UBM essential for specific types of trauma, congenital anomalies, and anterior segment tumors, UBM imaging has found clinical utility in a broad spectrum of diseases for structural assessments not limited to the anterior intraocular anatomy, but also for eyelid and orbit anatomy. This imaging tool has a very specific niche in the pediatric population where anterior segment disease can be accompanied by corneal opacity or clouding, and anomalies posterior to the iris may be present. Pediatric patients present additional diagnostic challenges. They are often unable to offer detailed histories or fully cooperate with examination, thus amplifying the need for high-resolution imaging. This purpose of this systematic review is to identify and synthesize the body of literature involving use of UBM to describe, evaluate, diagnose, or optimize treatment of pediatric ocular disease. The collated peer-reviewed research details the utility of this imaging modality, clarifies the structures and diseases most relevant for this tool, and describes quantitative and qualitative features of UBM imaging among pediatric subjects. This summary will include information about the specific applications available to enhance clinical care for pediatric eye disease.
\end{abstract}

\section{Introduction}

The concept of ultrasound biomicroscopy (UBM) specifically for ocular tissue was first introduced by Marmor who used a probe frequency of $1000 \mathrm{MHz}$ on postmortem eyes

Supplementary information The online version of this article (https:// doi.org/10.1038/s41433-020-01184-4) contains supplementary material, which is available to authorized users.

Janet L. Alexander

jalexander@som.umaryland.edu

1 Department of Ophthalmology and Visual Sciences, University of Maryland School of Medicine, 419 West Redwood Street, Suite 479, Baltimore, MD 21201, USA

2 University of Maryland School of Medicine, 419 West Redwood Street, Suite 479, Baltimore, MD 21201, USA

3 Children's Hospital Los Angeles \& The USC Roski Eye Institute, USC Keck School of Medicine, 4650 Sunset Blvd., Mailstop \#88, Los Angeles, CA 90027, USA

4 Health Sciences and Human Services Library, University of Maryland, 601W Lombard Street, Baltimore, MD 21201-1512, USA to obtain images of the human retina at resolutions comparable to light microscopy [1]. Ophthalmic use of UBM was refined for in vivo use by Pavlin as an adaptation of ultrasound technology, providing high-resolution images of the anterior eye [2]. The modification on existing ultrasound tools required an increase in ultrasound transducer frequency. This dramatically enhances image resolution for small structural anatomy, but results in less depth of sound wave penetration, as high frequency sound waves attenuate more quickly than low frequency sound waves. In the original Pavlin paper, a frequency of $100 \mathrm{MHz}$ was used, but frequencies in the range of $35-50 \mathrm{MHz}$ offer the optimal balance of resolution and depth of penetration for the anterior chamber for most applications (Table 1). Anterior segment optical coherence tomography (AS-OCT) was introduced in 1994, soon after UBM, ultimately rendering the use of the highest frequency transducers less relevant [3]. The advantage of penetration depth became the key driving force making this device an indispensable clinical tool that AS-OCT could complement, but not replace.

As the pioneering team led by Pavlin reported clinical results over the decade following their introductory paper, numerous ophthalmologists followed suit. This new 
Table 1 Summary of ocular ultrasonic biomicroscopy frequencies.

\begin{tabular}{|c|c|c|c|c|c|c|}
\hline $\begin{array}{l}\text { Transducer } \\
\text { Frequency }\end{array}$ & $\begin{array}{l}\text { Lateral } \\
\text { Resolution } \\
* \text { (Axial) }\end{array}$ & $\begin{array}{l}\text { Depth of } \\
\text { Tissue } \\
\text { Penetration } \\
\text { (Focal } \\
\text { Zone) }\end{array}$ & $\begin{array}{l}\text { Clinical } \\
\text { Applications }\end{array}$ & Advantages & Disadvantages & \\
\hline $10 \mathrm{MHz}$ & $\begin{array}{l}120-400 \\
\mu \mathrm{m}(50- \\
200)\end{array}$ & $25 \mathrm{~mm}$ & $\begin{array}{l}\text { Retina, optic } \\
\text { nerve, orbit }\end{array}$ & $\begin{array}{l}\text { Ability to view } \\
\text { entire eye and } \\
\text { surrounding } \\
\text { tissue }\end{array}$ & $\begin{array}{l}\text { Relatively low } \\
\text { resolution }\end{array}$ & \\
\hline $20-25 \mathrm{MHz}$ & $\begin{array}{l}120-250 \\
\mu \mathrm{m}(70- \\
100)\end{array}$ & $20-25 \mathrm{~mm}$ & $\begin{array}{l}\text { Retina, posterior } \\
\text { lens }\end{array}$ & $\begin{array}{l}\text { Optimal } \\
\text { frequency for } \\
\text { full globe } \\
\text { imaging. }\end{array}$ & $\begin{array}{l}\text { No useful view of } \\
\text { the anterior } \\
\text { segment }\end{array}$ & \\
\hline $35-40 \mathrm{MHz}$ & $\begin{array}{l}30-120 \\
\mu \mathrm{m}(23- \\
60)\end{array}$ & $5-6 \mathrm{~mm}$ & $\begin{array}{l}\text { Anterior } \\
\text { segment, } \\
\text { posterior lens, } \\
\text { ciliary body, } \\
\text { anterior vitreous }\end{array}$ & $\begin{array}{l}\text { Good } \\
\text { resolution, } \\
\text { depth of view } \\
\text { includes } \\
\text { deeper anterior } \\
\text { chamber } \\
\text { structures }\end{array}$ & $\begin{array}{l}\text { Somewhat low } \\
\text { resolution for } \\
\text { superficial } \\
\text { anatomy }\end{array}$ & Need for \\
\hline $45-50 \mathrm{MHz}$ & $\begin{array}{l}30-70 \mu \mathrm{m} \\
(15-50)\end{array}$ & $4-5 \mathrm{~mm}$ & $\begin{array}{l}\text { Anterior } \\
\text { segment, better } \\
\text { resolution for } \\
\text { corneal imaging, } \\
\text { Schlemm's } \\
\text { canal }\end{array}$ & $\begin{array}{l}\text { Very good } \\
\text { resolution }\end{array}$ & $\begin{array}{l}\text { Limited depth of } \\
\text { penetration }\end{array}$ & $\begin{array}{l}\text { supine } \\
\text { position, } \\
\text { cooperation, } \\
\text { and } \\
\text { immersion } \\
\text { (using "shell }\end{array}$ \\
\hline $100 \mathrm{MHz}$ & $15-20 \mu \mathrm{m}$ & $3.5-4 \mathrm{~mm}$ & $\begin{array}{l}\text { Cornea, angle, } \\
\text { anterior iris and } \\
\text { anterior lens }\end{array}$ & $\begin{array}{l}\text { Excellent } \\
\text { resolution }\end{array}$ & $\begin{array}{l}\text { Poor depth of } \\
\text { penetration }\end{array}$ & $\begin{array}{l}\text { and gel'") or } \\
\text { bubble } \\
\text { (disposable }\end{array}$ \\
\hline$>100 \mathrm{MHz}$ & $10 \mu \mathrm{m}$ & $<3.5 \mathrm{~mm}$ & $\begin{array}{l}\text { Cornea, } \\
\text { conjunctiva, } \\
\text { superficial skin } \\
\text { layers }\end{array}$ & $\begin{array}{l}\text { Marginal } \\
\text { improvement } \\
\text { in resolution as } \\
\text { frequencies } \\
\text { increase } \\
\text { beyond } 100 \\
\text { MHz. Little } \\
\text { advantage over } \\
\text { AS-OCT. }\end{array}$ & $\begin{array}{l}\text { Cost, availability, } \\
\text { increased signal } \\
\text { to noise ratio. AS- } \\
\text { OCT generally } \\
\text { better for the rare } \\
\text { ultra-high } \\
\text { frequency } \\
\text { applications }\end{array}$ & $\begin{array}{l}\text { water sealed } \\
\text { sterile } \\
\text { membrane) }\end{array}$ \\
\hline $\begin{array}{l}\text { AS-OCT } \\
\text { (for } \\
\text { comparison) }\end{array}$ & $15 \mu \mathrm{m}$ & $\begin{array}{l}\text { Maximum } \\
6 \text { mm (if } \\
\text { media } \\
\text { clear, } \\
\text { generally } \\
\text { depth is } \\
\text { limited by } \\
\text { iris surface) }\end{array}$ & $\begin{array}{l}\text { Cornea, angle, } \\
\text { anterior iris and } \\
\text { anterior lens }\end{array}$ & $\begin{array}{l}\text { Excellent } \\
\text { resolution, } \\
\text { non- contact }\end{array}$ & $\begin{array}{l}\text { Poor depth of } \\
\text { penetration, no } \\
\text { view through } \\
\text { corneal opacity, } \\
\text { no view posterior } \\
\text { to the iris, } \\
\text { requires fixation }\end{array}$ & \\
\hline
\end{tabular}


imaging tool quickly developed a niche in ophthalmic imaging due to its ability to image through corneal opacities, assess anterior segment tumors, introduce a method for quantitative gonioscopy, and better define the relationships among structures to understand disease mechanisms. These applications merely scratched the surface of the available clinical applications of a shallow depth yet highresolution imaging tool unrestrained by the need for light penetration.

This review explores the utility of UBM in better understanding pediatric ocular anatomy and assesses the role of UBM in the diagnosis and management of pediatric ocular conditions, including cataract, glaucoma, uveitis, tumors, and ocular trauma. Results address UBM equipment, the pediatric diseases of interest, and the specific applications and outcomes of UBM imaging in pediatric studies.

\section{Methods}

\section{Search methods for identification of studies}

A research librarian constructed and executed database searches in MEDLINE (PubMed), Embase (Elsevier), and Cochrane Central Register of Controlled Trials (Wiley) in July 2020. Search strategies were comprised of two concepts: UBM and children. A combination of text words and database-specific terminology (e.g., MeSH) were used. The search was not restricted by language or date of publication. The complete PubMed strategy can be found in Supplementary Material. References of included studies were reviewed for relevance. Covidence was used to manage and detect duplicate references and for screening purposes.

\section{Study selection and eligibility}

An initial screening of titles and abstracts was first performed to identify possible relevant studies. Duplicate articles were removed from the initial database search, and the list of references was managed with Covidence. Articles were screened independently by two authors (JLA and LW). If necessary, a third author (JP) resolved any disagreements. The full texts of identified studies were examined. Full-text articles were screened independently by two authors (JLA and JP). We did not require blinding of assessors. Studies were eligible if they met the following criteria: (1) use of cohort, case-control, or cross-sectional study design; (2) study population included enrollment of at least four pediatric subjects age $0-18$ years old (inclusion of adults was not grounds for exclusion as long as the minimum pediatric enrollment was met); (3) use of UBM was explicitly stated and results of UBM were reported.
Inclusion criteria:

- Human studies using UBM to diagnose, predict, or guide management.

- Observational or comparative studies of UBM findings.

- Pediatric studies with $\geq 4$ subjects age $\leq 18$ years.

\author{
Exclusion criteria: \\ - Adult studies with sub- \\ ject ages $>18$ years. \\ (Predominantly adult \\ studies with $\leq 3$ pediatric \\ subjects were reviewed \\ separately.) \\ - Case reports (reviewed \\ separately). \\ - Case series with $\leq 3$ sub- \\ jects (reviewed sepa- \\ rately). \\ - Review articles. \\ - Studies lacking use of \\ UBM or not reporting \\ UBM results.
}

\section{Data extraction}

Covidence was used as an initial organizational tool to extract the interventions, outcomes, and population characteristics of each study. A Google Sheets spreadsheet was then used to categorize the articles into subtypes according to the number of pediatric subjects included. Studies with four or more pediatric subjects were included for detailed extraction. Studies with few pediatric subjects $(n=3$ or less) were evaluated separately as "case reports or small series". Outcomes were subcategorized by type of study design, UBM platform used, probe frequency used, clinical application including broad disease category (i.e., glaucoma, trauma, uveitis) and specific disease category (i.e., glaucoma following congenital cataract surgery, traumatic cyclodialysis, and toxocara uveitis), anatomy of interest, and outcomes including the quantitative and qualitative utility of UBM reported. Data extraction were done by three authors (JLA, JP, and AD) and complete extraction was rereviewed by two authors (JLA and JP). Google Translate was used for data extraction from non-English publications.

\section{Search results}

There was a total of 1597 records across all databases (Ovid MEDLINE, Cochrane CENTRAL, and EMBASE). Covidence identified 350 duplicates, leaving 1247 records to screen. Nine hundred and eighty-five studies were excluded in the title and abstract screening and another 146 studies were excluded in the full-text screening. The most common reasons for exclusion were studies that had only adult subjects, were unavailable, or did not use UBM. The screening process as well as exclusion reasons are illustrated in Fig. 1. One hundred and sixteen studies were 
included for complete data extraction. Sixty-six studies were separately reviewed as case reports and small series to determine UBM equipment type and diseases of interest.

\section{Results}

A summary of the included studies regarding UBM equipment type and study design are shown in Table 2.

\section{Global perspective of the literature}

The body of literature focused on pediatric applications for UBM imaging includes numerous case reports $(n=32)$ and small series $(n=34)$, as well as larger studies $(n=116)$, most of which had prospective design (58\%) and assessed quantitative and clinical outcomes. Only 59\% of papers explicitly stated the UBM platform and probe frequency used. Among those, the vast majority of studies utilized at $50 \mathrm{MHz}$ probe. In studies published prior to 2004, the Humphrey-Zeiss UBM Model 840 (San Leandro, CA [50 $\mathrm{MHz}]$ ) was the sole equipment reported. Studies published after 2004 reported a variety of vendors and models.

The clinical focus of case reports and small series differed from that of the larger studies. Among small studies, trauma was the most common clinical topic. Case reports and small series may offer a foundation to suggest specific

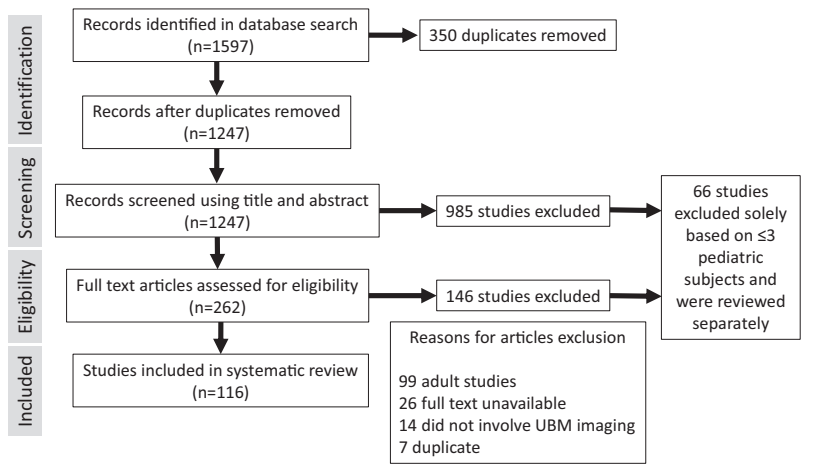

Fig. 1 Systematic review diagram. Flow diagram of study selection process. clinical conditions that could benefit from larger formal studies on pediatric UBM assessment.

Diseases of the pediatric anterior segment were key diseases of focus in the literature evaluating pediatric use of UBM imaging. These diseases are heterogenous and rare. In order of incidence, cataract $(1-15: 10,000)$ [4], trauma $(5: 10,000)$ [5], uveitis $(3-6: 100,000)[6,7]$, congenital corneal opacities including anterior segment dysgenesis (3-6:100,000) [8], glaucoma $(2: 100,000)[9,10]$, and aniridia $(1-2: 100,000)$ [11] combine to account for the majority of treatable childhood blindness [12]. In particular pediatric UBM use, glaucoma, intraocular mass lesions, uveitis, cataract and other lens abnormalities, and cornea were the five most commonly published disease categories, respectively (Fig. 2). Extraocular muscle and eyelid studies using UBM among pediatric subjects have grown since these applications were first published in 2002 and 2004, respectively $[13,14]$. Genetic disease evaluation, in particular genotype-phenotype correlations have offered some novel insights to the known natural history of diseases such as cystinosis [15], and neurofibromatosis type 1 [16]. The combination of rarity of disease, and challenge of patient cooperation for imaging are likely reasons these types of studies, while valuable, are infrequent.

\section{Key pediatric disease insights offered by UBM}

\section{Glaucoma}

The 22 publications evaluating UBM use in the setting of childhood glaucoma combined to contribute a total of 890 eyes from 557 pediatric subjects. More recently published pediatric glaucoma studies were generally of good quality, including a large proportion of quantitative data, comparative studies, prospective design, and some studies incorporated blinding of observers.

The primary subtype of pediatric glaucoma evaluated using pediatric UBM was primary congenital glaucoma (PCG). Sixty percent of the included glaucoma literature had

Table 2 Studies evaluating pediatric use of UBM.

\begin{tabular}{|c|c|c|c|}
\hline & Large case series or comparative studies & Case reports and small case series & Total \\
\hline Number of published studies & 116 & 66 & 182 \\
\hline $\begin{array}{l}\text { Study reported probe transducer frequency, } \\
\text { percent (number) }\end{array}$ & $59 \%(68)$ & $52 \%(34)$ & $55 \%(101)$ \\
\hline Using $50 \mathrm{MHz}$ probe ${ }^{\mathrm{a}}$, percent (number) & $74 \%(50)$ & $82 \%(28)$ & $77 \%(78)$ \\
\hline Prospective & $58 \%(67)$ & N/A & \\
\hline Most common clinical applications & $\begin{array}{l}\text { Glaucoma, ocular mass lesion, uveitis, } \\
\text { and lens/cataract }\end{array}$ & $\begin{array}{l}\text { Trauma, ocular mass lesion, glaucoma, } \\
\text { and retina/choroid }\end{array}$ & \\
\hline
\end{tabular}

${ }^{\mathrm{a} A m o n g}$ studies reporting probe frequency. 
Fig. 2 Summary of disease types. Disease categories evaluated by UBM in pediatric populations by number of publications.

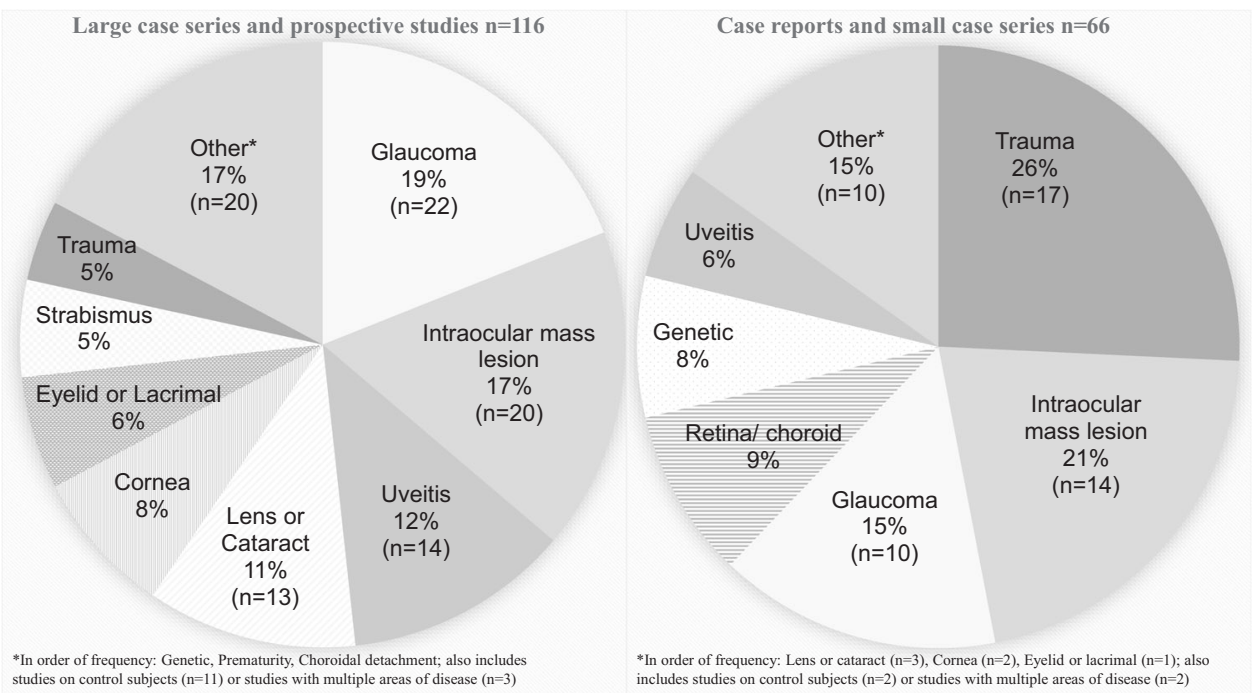

subjects with PCG. Other glaucoma aetiologies included glaucoma following congenital cataract surgery, mechanical angle obstruction (due to angle closure, plateau configuration, anterior segment mass lesions including melanoma, nanophthalmos, and Weill-Marchesani syndrome), and ocular and systemic syndromes (anterior segment dysgenesis, aniridia, Sturge Weber syndrome, and Neurofibromatosis Type 1). Genotype-phenotype correlations were reported using UBM for CYP1B1 [17] and Axenfeld-Rieger syndrome candidate genes (PITX2, FOXC1, and PRDM5) [18]. No association was found between CYP1B1 mutation and iridocorneal or keratolenticular adhesions. UBM was used to identify aniridia-subtype of Axenfeld-Rieger syndrome in subjects with PITX2 mutations.

Five studies evaluated postoperative structural anatomy using UBM. Surgical planning or evaluation of surgical results related to predicting surgical outcomes and risk factors, monitoring blebs, and integrating structural information into surgical plans was performed.

Seven studies compared subjects with various subtypes of pediatric glaucoma to matched controls. Data from casecontrol studies looking specifically at congenital glaucoma are shown in Table 3 [19-25]. Case-control UBM studies evaluating congenital glaucoma focused on variable structural anatomy, but for studies with overlapping content, many results were reproduced. Consistent findings across multiple studies included increased anterior chamber depth, larger iridocorneal angles, smaller or nonexistent Schlemm's canal, smaller or thinner ciliary body, and elongated zonules among subjects with congenital glaucoma compared to controls. Although the many unique features quantitatively detailed in the case-control studies in Table 3 have been corroborated by multiple studies, they have not yet been evaluated in cohort studies as potential markers for disease diagnosis or risk factors for progression.
Studies utilizing UBM for the diagnosis or management of glaucoma found this imaging tool to provide key information regarding concurrent anomalous structures, and for surgical planning.

\section{Intraocular mass lesions}

Intraocular mass lesions are key pediatric diseases evaluated using UBM. Among the reviewed case reports and small series, $50 \%$ of publications focused on iridociliary cysts and $50 \%$ evaluated small solid tumors of various subtypes but not including retinoblastoma. Among larger studies included in this systematic review, $45 \%$ were focused on retinoblastoma, the most common intraocular malignancy in children. Twenty-five percent were dedicated to evaluation of iridociliary cysts, and the remaining $30 \%$ evaluated various solid tumor subtypes.

In the diagnostic evaluation of children with retinoblastoma, $10 \mathrm{MHz}$ b-scan probes are routinely used to identify a retinal-based lesion with intra-tumoral foci of calcification, which is pathognomonic for this intraocular cancer. Ultrasonography can also be used to monitor for regression in the overall volume of the tumor with globe-sparing therapy. UBM is indicated to evaluate for anterior tumor extension including tumor anterior to the anterior vitreous face and tumor touching the lens, features that indicate very advanced intraocular disease (Group E) [26]. In a study of 50 children with advanced retinoblastoma in India, UBM was both highly sensitive (100\%) and specific (95\%) for anterior segment involvement, which correlated with high-risk histopathologic features [27]. A more recent indication for UBM in retinoblastoma involves evaluation for tumor involvement of the ciliary body prior to intravitreal injection of chemotherapy. The use of UBM to rule out ciliary body involvement is a critical first step in the safety-enhanced procedure for 


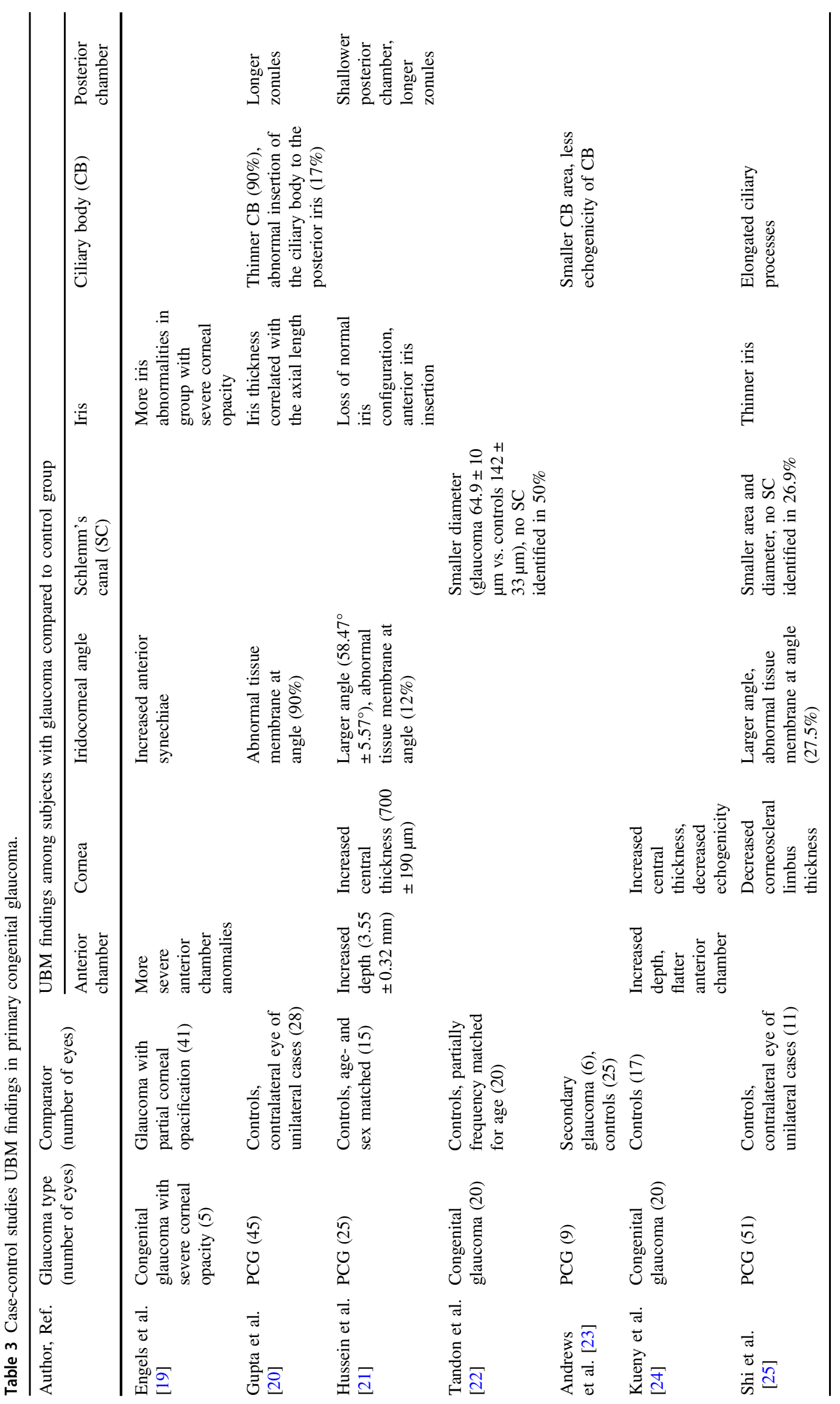


intravitreal injection described by Munier [28]. Due to the enhanced safety profile now in place, aided by UBM imaging, intravitreal chemotherapy injections are routinely done and have been found to be safe and highly efficacious for the treatment of vitreous seeding and intracameral seeding in retinoblastoma [29].

\section{Uveitis}

Combined data from the 14 uveitis papers included in this review involved a combined total of 620 pediatric subjects and 838 eyes. Among these publications, five were focused specifically on toxocara uveitis $(N=324$ pediatric subjects, 353 eyes). The majority of these subjects were school-age children with significant visual compromise. Toxocara features specifically identified using UBM included: vitreal changes (described variably as condensations, strands, or membranes) in $68-87 \%$ of cases, peripheral retinal granuloma $(60 \%)$, pseudocysts, thickened ciliary body, tractional cyclodialysis (41\%), peripheral retinal detachment, iris traction, and peripheral anterior synechiae. All studies noted that peripheral retinal granuloma was approximately twice as common as posterior granuloma. One study noted $80 \%$ of peripheral granulomas were located on the surface of the ciliary body, further emphasizing the diagnostic utility of UBM [30]. UBM identified $95 \%$ of peripheral granulomas compared to intraoperative evaluation [31]. Compared with indirect ophthalmoscope, statistical analysis showed significant differences in the number of clock hours of peripheral pathology detected by UBM [32]. In summary, all toxocariasis studies found UBM to improve the detection rate of peripheral granulomas, which were more common than posterior granulomas. UBM demonstrated value and reliability as a diagnostic tool for pediatric patients with ocular toxocariasis.

Additional key uses of UBM among pediatric subjects with uveitis were to evaluate causes of hypotony, presence of pars planitis, and to evaluate for toxocara uveitis. Other reported uses include a general assessment of inflammatory lesions of the iris, ciliary body, pars plana, and peripheral vitreous in infectious, autoimmune, and idiopathic cases. Specific features of pediatric uveitis on UBM were damage to ciliary processes (most commonly in the inferior quadrant), and granulomas (most commonly in the temporal quadrant). Ciliary atrophy in two studies was found to be predictive of response to treatment $[33,34]$. Studies reported that UBM improved detection of complications, diagnosis, and management in pediatric uveitis. Clinical indication to use UBM in pediatric uveitis is likely $8 \%$ overall, and up to $90-100 \%$ in subsets of specific uveitis aetiologies and complications, such as toxocariasis and hypotony.

\section{Lens and cataract}

The body of literature on UBM for pediatric cataracts evaluates the anatomy at each relevant step in the congenital cataract lifecycle: diagnosis and preoperative planning, surgical removal, and postoperative assessment generally dedicated to assessing intraocular lens (IOL) position. Fifty-seven percent of publications evaluated the position and visual outcome for various IOL types and locations including bag, sulcus, scleral fixated, and iris claw [35-42]. The remaining $43 \%$ of publications evaluated pre- and postoperative anatomy. Preoperative evaluations quantified anterior chamber anatomy and assisted in surgical management of capsular anomalies (posterior defects and membranous cataracts) [4345]. Postoperative studies focused on the anatomy of aphakia [46] and wound healing [47]. A single case-control comparison study evaluated quantitative postoperative congenital cataracts to control eyes [48]. Additional case-control and cohort studies are needed in this area to generate consensus on the anatomic changes and clinical implications of congenital and childhood cataract surgery.

\section{Ocular trauma}

Nine papers were identified that described the use of UBM in ocular trauma. Fifty-six percent of the studies looked at either specific qualitative UBM features or UBM evaluation of post-traumatic sequelae such as traumatic iris cysts or corneal scarring. The remaining $44 \%$ of papers evaluated the use of UBM in the setting of ocular trauma.

The largest study evaluating the use of UBM in ocular trauma, performed in Montreal, Canada, included 109 eyes. The authors concluded that UBM was superior to other methods including CT and B-Scan in evaluating the zonular status, as well as in identifying angle recession, cyclodialysis, and superficial intraocular foreign bodies [49]. Another study investigated the role of UBM in identifying suspected anterior segment foreign bodies in 59 eyes. UBM successfully identified foreign bodies in the cornea, conjunctiva, iris, lens, sclera, iridocorneal angle, and ciliary body. Different types of foreign materials including metal, glass, and organic materials were identified. The authors concluded that UBM is useful in localizing anterior segment foreign bodies, and plays an important role in therapeutic planning [50]. Two studies evaluated the use of UBM in ocular fireworks trauma. In the first study, UBM was performed in 32 eyes with severe closed-globe injuries leading to hazy media at the Persian fireworks festival. UBM was effective in identifying iridodialysis, cyclodialysis, angle recession, lens subluxation, and anterior segment foreign body in these patients. Many of these findings were not identified on clinical examination, and were only found upon UBM imaging, illustrating the value of UBM as an essential tool in the assessment of subclinical 
injury to the anterior segment, particularly in the setting of explosive or ballistic injury mechanism [51]. Another study evaluated 53 eyes of patients who had fireworks related injuries in Southern China. The authors found that UBM was helpful in the making the correct diagnosis and treatment plan in these traumatized eyes [52]. These studies evaluating UBM use in trauma included pediatric subjects, but were not exclusively focused on the pediatric age group.

In summary, UBM has been evaluated as an imaging tool in the evaluation of anterior segment ocular trauma in four major studies, including 253 eyes. These findings demonstrate that UBM is an important tool in evaluating anterior segment abnormalities including zonular loss, angle recession, lens subluxation, cyclodialysis, and foreign body. UBM is effective in identifying subclinical abnormalities, not visible on clinical exam and may be invaluable in surgical planning and therapeutic management.

\section{Cornea}

The most common topic of literature evaluating use of UBM in pediatric subjects with corneal pathology was congenital corneal opacities (CCO), including but not limited to the spectrum of anterior segment dysgenesis. Key findings from these studies include: (1) AS-OCT and UBM can be used interchangeably for corneal thickness and depth measurements in patients with CCO [53], (2) in cases of $\mathrm{CCO}$ with penetrating keratoplasty histopathological correlation, UBM diagnosis was correct $100 \%$ of cases while clinical diagnosis prior to UBM was correct in $62 \%$ of cases [54], (3) UBM informs genotype-phenotype correlations [54], (4) UBM assisted in both diagnosis and treatment decisions for $\mathrm{CCO}$ [55-59]. Other pediatric corneal diseases evaluated using UBM includes keratoconus (acute hydrops [60, 61], and intrastromal ring implantation [62]), and deep anterior lamellar keratoplasty (DALK) outcomes and indications [63]. Normal corneal growth evaluation using UBM identified and quantified structures with statistically significant differences in younger eyes, and provided baseline reference values for comparison in future studies [64].

\section{Beyond the anterior segment: eyelid, lacrimal, strabismus, and retina}

The rare ability of UBM to provide quantitative imaging information to all structures of the eye yields information about such diverse clinical situations as the level of anesthesia [65], the status of dermatitis, the location of extraocular muscle insertion, thickness of the levator complex in congenital ptosis, and the diameter of the canalicular apparatus.

Evaluation of extraocular muscle insertions in the setting of strabismus was evaluated in six studies. All studies concluded that recti muscle insertions can be well localized using UBM [13, 66-68], with less accuracy for lateral rectus position noted in only one study [69]. In general measurements greater than $15 \mathrm{~mm}$ were the least accurate [70], suggesting postoperative localization of the lateral and superior rectus may be most difficult to measure using current UBM technology.

Pediatric eyelid and lacrimal evaluations using UBM revealed that congenital ptosis, and outcomes of congenital ptosis surgery could be evaluated using UBM. Thinning of the levator aponeurosis correlated closely with ptosis [14, 71, 72]. UBM measurement before and after retroorbicularis oculus fat resection likewise correlated closely with postoperative outcomes [73]. Various pediatric periorbital dermatologic conditions such as port wine stain, morphea, and chronic eczema demonstrated classic diagnostic patterns on UBM imaging that correlated directly with histopathology [74]. Lacrimal system evaluation has been carried out using UBM to analyse both structure and function in patients of all ages, including pediatric, and in several lacrimal conditions: chronic dacryocystitis, fistula, mucocoele, dacryolith, silicone lacrimal intubation, congenital and acquired canalicular obstruction, Down's syndrome, and facial nerve palsy [75, 76].

Neoplastic and uveitic applications (retinoblastoma and toxocariasis, respectively) are the most prominent posterior segment applications of UBM. Additional publications utilizing UBM to evaluate the pediatric posterior segment included correlation of scleral transillumination to UBM images for localization of intravitreal injection or sclerotomy site [77] and evaluation for choroidal detachment in the setting of rhegmatogenous retinal detachment [78].

\section{The structural anatomy of the pediatric eye}

In order to fully appreciate the quantitative features of UBM imaging in pediatric disease, a sophisticated understanding of normal structural anatomy is essential. In this systematic review, 13 studies were identified that evaluated normal pediatric anatomy using UBM. Three of these studies focused on premature infants [79-81], and four focused on anterior segment changes concurrent with accommodation and dilation [65, 82-84]. These studies provide useful normative data [64, 85-87], and emphasize the importance of controlling for age and environmental factors during UBM imaging.

\section{Future directions}

UBM imaging has matured over the last 30 years, yet ample space for improvement still exists in technology development and clinical use cases. Opportunity remains in augmenting various steps in the process from image 
acquisition to image analysis. Hardware, software, dual modality, automated and artificial intelligence (AI) image analysis, and novel clinical applications are on the horizon.

In terms of hardware advances, future UBM transducers will include features that enhance image resolution. The most essential component of transducer function is the piezoelectric element. Function of this element relies heavily on the substance material properties, and micromachining techniques. Future advancements in both materials science [88] and micromachining (i.e., mechanical dicing, and ceramic layering for middle frequency ocular ultrasound $10-35 \mathrm{MHz}$ [89]; etching, bonding, and lasering for higher frequency ultrasound fabrication $50-65 \mathrm{MHz}[90,91])$ will likely improve the capability of this element, which is highly dependent on electrical properties. Many such technologies are under active development including high frequency linear arrays allowing for more dynamic imaging with high frame rates by using electronic rather than mechanical scanning [92].

Combined modality imaging is another potential future advancement that can expand the capability of standard UBM. Augmenting ultrasonic imaging of substructures with optical technology for enhanced image resolution of superficial structures may offer clinicians the best of both worlds. UBM combined with scanning time-resolved optical spectroscopy technologies (fluorescence and reflectance spectroscopy) has shown enhanced tissue diagnostic features [93]. Several additional bimodal techniques show promise for future clinical applications and potentially enhanced in vivo diagnosis.

Advances in image analysis have improved the timeintensive process of UBM image analysis, most commonly by using macros in Matlab and ImageJ [94, 95]. Automation can be further advanced with higher level computer programming in programs such as Python [96]. AI applications of UBM image analysis have been published among adult subjects [97], leaving pediatric UBM image analysis using $\mathrm{AI}$ an understudied area of great potential.

Identifying novel clinical applications, particularly in pediatric populations, is key to realizing the full potential of UBM. Remarkable breadth of pediatric disease has already been evaluated with this technology to assist in evaluation of every ocular and orbital tissue from skin, muscle, and fat to the retina and ciliary body. Unfortunately, numerous pediatric diseases remain unexplored using UBM, in particular many genetic syndromes and surgical outcomes. Clinically, intraoperative UBM may have future applications in pediatric ophthalmic disease. Given the growing popularity of intraoperative AS-OCT, and the pattern of parallel advancements of these two technologies, intraoperative UBM is a logical future step for diagnostic/therapeutic UBM applications in pediatric eye disease. Intraoperative UBM has been reported in adult subjects [98] and in a single pediatric case report [99], but the full potential of UBM intraoperatively has probably not yet been realized.

\section{Conclusion}

Four decades ago, Pavlin, Sherar, and Foster set out to develop "an apparatus to be used in the clinical setting for examining anterior structures of the eye not visible by [then] current techniques". Their team's vision to create a tool capable of imaging parts of the eye otherwise not directly viewable opened up new possibilities, influencing the ophthalmic assessment of not only the anterior segment, but also the eyelid, extraocular muscles, and the posterior segment. Pediatric eye disease, and in particular diseases of the anterior segment, can be associated with compromised view through the cornea and disorganized anatomy, two areas where UBM technology is the only available highresolution imaging modality.

By better understanding features of the pediatric eye that have been previously studied, we aim to bring attention to the areas of study that are lacking, in particular quantitative outcomes assessments, longitudinal or cohort studies to identify clinically relevant risk factors for clinical worsening or improvement, interventional cohort studies, and continued evaluation of the structural anatomy of the anterior segment that contributes to disease.

Funding JLA has grant support from the UMB ICTR/Clinical Science and Translational Science KL2 Award 1KL2TR003099-01 and R43EY030798-01. JLB has grant support from National Cancer Institute of the NIH Award K08CA232344, Hyundai Hope on Wheels, and The Wright Foundation. JLB has indirect support provided by The Larry and Celia Moh Foundation, The Institute for Families, Inc., Children's Hospital Los Angeles, an unrestricted departmental grant from Research to Prevent Blindness, The National Institute of Health P30EY029220, The National Cancer Institute P30CA014089.

\section{Compliance with ethical standards}

Conflict of interest The authors declare that they have no conflict of interest.

Publisher's note Springer Nature remains neutral with regard to jurisdictional claims in published maps and institutional affiliations.

\section{References}

1. Marmor MF, Wickramasinghe HK, Lemons RA. Acoustic microscopy of the human retina and pigment epithelium. Invest Ophthalmol Vis Sci. 1977;16:660-6.

2. Pavlin CJ, Sherar MD, Foster FS. Subsurface ultrasound microscopic imaging of the intact eye. Ophthalmology. 1990;97:244-50. https://doi.org/10.1016/S0161-6420(90)32598-8.

3. Izatt JA, Hee MR, Swanson EA, et al. Micrometer-scale resolution imaging of the anterior eye in vivo with optical coherence tomography. Arch Ophthalmol. 1994;112:1584-9. https://doi.org/ 10.1001/archopht.1994.01090240090031.

4. Yi J, Yun J, Li Z-K, Xu C-T, Pan B-R. Epidemiology and molecular genetics of congenital cataracts. Int J Ophthalmol. 2011;4:422-32. https://doi.org/10.3980/j.issn.2222-3959.2011.04.20. 
5. Cillino S, Casuccio A, Di Pace F, Pillitteri F, Cillino G. A fiveyear retrospective study of the epidemiological characteristics and visual outcomes of patients hospitalized for ocular trauma in a Mediterranean area. BMC Ophthalmol. 2008;8:6. https://doi.org/ 10.1186/1471-2415-8-6.

6. Päivönsalo-Hietanen T, Tuominen J, Saari KM. Uveitis in children: population-based study in Finland. Acta Ophthalmol Scand. 2000;78: 84-8. https://doi.org/10.1034/j.1600-0420.2000.078001084.x.

7. Edelsten C, Reddy MA, Stanford MR, Graham EM. Visual loss associated with pediatric uveitis in english primary and referral centers. Am J Ophthalmol. 2003;135:676-80. https://doi.org/10. 1016/s0002-9394(02)02148-7.

8. Kurilec JM, Zaidman GW. Incidence of Peters anomaly and congenital corneal opacities interfering with vision in the United States. Cornea. 2014;33:848-50. https://doi.org/10.1097/ICO. 0000000000000182.

9. Biglan AW. Glaucoma in children: are we making progress? J AAPOS. 2006;10:7-21. https://doi.org/10.1016/j.jaapos.2005.10. 001.

10. Aponte EP, Diehl N, Mohney BG. Incidence and clinical characteristics of childhood glaucoma: a population-based study. Arch Ophthalmol. 2010;128:478-82. https://doi.org/10.1001/archophtha lmol.2010.41.

11. Nelson LB, Spaeth GL, Nowinski TS, Margo CE, Jackson L. Aniridia. A review. Surv Ophthalmol. 1984;28:621-42. https:// doi.org/10.1016/0039-6257(84)90184-x.

12. Zetterström C, Lundvall A, Kugelberg M. Cataracts in children. J Cataract Refract Surg. 2005;31:824-40. https://doi.org/10.1016/j. jcrs.2005.01.012.

13. Watts P, Smith D, MacKeen L, Kraft S, Buncic JR, Abdolell M. Evaluation of the ultrasound biomicroscope in strabismus surgery. $\mathrm{J}$ AAPOS. 2002;6:187-90. https://doi.org/10.1067/mpa.2002.122365.

14. Hoşal BM, Ayer NG, Zilelioğlu G, Elhan AH. Ultrasound biomicroscopy of the levator aponeurosis in congenital and aponeurotic blepharoptosis. Ophthalmic Plast Reconstr Surg. 2004;20:308-11. https://doi.org/10.1097/01.IOP.0000129532.33913.E7.

15. Mungan N, Nischal KK, Héon E, MacKeen L, Balfe JW, Levin AV. Ultrasound biomicroscopy of the eye in cystinosis. Arch Ophthalmol. 2000;118:1329-1333. https://doi.org/10.1001/a rchopht.118.10.1329.

16. Morales J, Chaudhry IA, Bosley TM. Glaucoma and globe enlargement associated with neurofibromatosis type 1. Ophthalmology. 2009;116:1725-30. https://doi.org/10.1016/j.ophtha.2009.06.019.

17. Kelberman D, Islam L, Jacques TS, et al. CYP1B1-related anterior segment developmental anomalies: Novel mutations for infantile glaucoma and von Hippel's ulcer revisited. Ophthalmology. 2011;118:1865-73. https://doi.org/10.1016/j.ophtha.2011.01.044.

18. Wang X, Liu X, Huang L, et al. Mutation survey of candidate genes and genotype-phenotype analysis in 20 Southeastern Chinese patients with Axenfeld-Rieger syndrome. Curr Eye Res. 2018;43:1334-41. https://doi.org/10.1080/02713683.2018.1493129.

19. Engels BF, Dietlein TS, Jacobi PC, Krieglstein GK. Ultrasound biomicroscopy diagnosis of congenital glaucoma. Klin Monbl Augenheilkd. 1999;215:338-41. https://doi.org/10.1055/s-20081034728.

20. Gupta V, Jha R, Srinivasan G, Dada T, Sihota R. Ultrasound biomicroscopic characteristics of the anterior segment in primary congenital glaucoma. J AAPOS. 2007;11:546-50. https://doi.org/ 10.1016/j.jaapos.2007.06.014.

21. Hussein TR, Shalaby SM, Elbakary MA, Elseht RM, Gad RE. Ultrasound biomicroscopy as a diagnostic tool in infants with primary congenital glaucoma. Clin Ophthalmol. 2014;8:1725-30. https://doi.org/10.2147/OPTH.S66682.

22. Tandon A, Watson C, Ayyala R. Ultrasound biomicroscopy measurement of Schlemm's canal in pediatric patients with and without glaucoma. J AAPOS. 2017;21:234-7. https://doi.org/10. 1016/j.jaapos.2017.03.011.

23. Andrews L, Kueny L, Martinez C, et al. Structural changes of the ciliary body and ciliary processes measured by ultrasound biomicroscopy of primary congenital glaucoma in comparison to glaucoma following congenital cataract surgery. J Am Assoc Pediatr Ophthalmol Strabismus. 2019;23:e15-6. https://doi.org/ 10.1016/j.jaapos.2019.08.049.

24. Kueny LS, Andrews L, Martinez C, et al. Structural changes of the anterior segment measured by ultrasound biomicroscopy in pediatric glaucoma. J Am Assoc Pediatr Ophthalmol Strabismus. 2019;23:e37. https://doi.org/10.1016/j.jaapos.2019.08.132.

25. Shi Y, Han Y, Xin C, et al. Disease-related and age-related changes of anterior chamber angle structures in patients with primary congenital glaucoma: an in vivo high-frequency ultrasound biomicroscopybased study. PLoS ONE. 2020;15. https:// doi.org/10.1371/journal.pone.0227602.

26. Linn Murphree A. Intraocular retinoblastoma: the case for a new group classification. Ophthalmol Clin N Am. 2005;18:41-53. https://doi.org/10.1016/j.ohc.2004.11.003. viii

27. Chawla B, Bhaskaran K, Dada T, Bajaj MS, Kashyap S, Shende D. Evaluation of the role of ultrasound biomicroscopy in advanced retinoblastoma: a prospective study on Asian Indian children. Ophthalmic Genet. 2020;41:125-30. https://doi.org/10.1080/ 13816810.2020.1737946.

28. Munier FL, Soliman S, Moulin AP, Gaillard M-C, Balmer A, Beck-Popovic M. Profiling safety of intravitreal injections for retinoblastoma using an anti-reflux procedure and sterilisation of the needle track. Br J Ophthalmol. 2012;96:1084-7. https://doi. org/10.1136/bjophthalmol-2011-301016.

29. Berry JL, Bechtold M, Shah S, et al. Not all seeds are created equal: seed classification is predictive of outcomes in retinoblastoma. Ophthalmology. 2017;124:1817-25. https://doi.org/10. 1016/j.ophtha.2017.05.034.

30. Chen Q, Gu J, Jiang R, Zhou M, Chang Q. Role of ultrasound biomicroscopy in diagnosis of ocular toxocariasis. $\mathrm{Br} \mathrm{J}$ Ophthalmol. 2018;102:642-6. https://doi.org/10.1136/bjophthalmol-2017310583.

31. Zhou M, Chang Q, Gonzales JA, et al. Clinical characteristics of ocular toxocariasis in Eastern China. Graefe's Arch Clin Exp Ophthalmol. 2012;250:1373-8. https://doi.org/10.1007/s00417012-1971-2.

32. Liu J, Li S, Deng G, Yang W, Chen W, Lu H. Ultrasound biomicroscopic imaging in paediatric ocular toxocariasis. Br J Ophthalmol. 2017;101:1514-7. https://doi.org/10.1136/bjophthalmol2016-309850.

33. da Costa DS, Lowder C, de Moraes HV Jr, Oréfice F. A relação entre o comprimento dos processos ciliares medidos pela biomicroscopia ultra-sônica e a duração, localização e gravidade das uveítes [The relationship between the length of ciliary processes as measured by ultrasound biomicroscopy and the duration, localization and severity of uveitis]. Arq Bras Oftalmol. 2006;69:383-8. 27492006000300018.

https://doi.org/10.1590/s0004-

34. Gupta P, Gupta A, Gupta V, Singh R. Successful outcome of pars plana vitreous surgery in chronic hypotony due to uveitis. Retina. 2009;29:638-43. https://doi.org/10.1097/IAE.0b013e31819a5fd8.

35. Long T, Xu Y, Wu X, Zhao J, Li Y, Xie L. IOL position [corrected] in pediatric eyes [published correction appears in Ophthalmology]. Ophthalmology. 2013;120:212-212.e2123. https:// doi.org/10.1016/j.ophtha.2012.08.039.

36. Zhao YE, Gong XH, Zhu XN, et al. Long-term outcomes of ciliary sulcus versus capsular bag fixation of intraocular lenses in children: an ultrasound biomicroscopy study. PLoS ONE. 2017;12. https://doi.org/10.1371/journal.pone.0172979. 
37. Arraes C, Endriss D, Lobato F, Arraes J, Ventura M. Subluxação congênita do cristalino: resultados visuais e posição das lentes intraoculares após a cirurgia [Congenital lens subluxation: visual acuity outcomes and intraocular lens postoperative position]. Arq Bras Oftalmol. 2010;73:171-4. https://doi.org/10.1590/s000427492010000200014.

38. Catal J, Cuadras D, Castany-Aregall M, et al. Anterior iris-claw intraocular lens implantation for the management of nontraumatic ectopia lentis: long-term outcomes in a paediatric cohort. 2017:170-4. https://doi.org/10.1111/aos.13192.

39. Rastogi A, Goray A, Thacker P, Kamlesh Babita. Assessment of the safety and efficacy of primary retropupillary fixation of irisclaw intraocular lenses in children with large lens subluxations. Int Ophthalmol. 2018;38:1985-92. https://doi.org/10.1007/s10792017-0688-y.

40. Rastogi A. Evaluation of functional outcome and stability of sutureless scleral tunnel fixated IOLs in children with ectopia lentis. Int J Ophthalmol. 2020;13:66-70. https://doi.org/10.18240/ ijo.2020.01.10.

41. Kamal AM, Hanafy M, Ehsan A, Tomerak RH. Ultrasound biomicroscopy comparison of ab interno and ab externo scleral fixation of posterior chamber intraocular lenses. J Cataract Refract Surg. 2009;35:881-4. https://doi.org/10.1016/j.jcrs.2009.01.006.

42. Sewelam A, Ismail AM, El Serogy H. Ultrasound biomicroscopy of haptic position after transscleral fixation of posterior chamber intraocular lenses. J Cataract Refract Surg. 2001;27:1418-22. https://doi.org/10.1016/s0886-3350(01)00791-x.

43. Long J, Xiang D, Guo Z, et al. Clinical characteristics and surgical procedures for children with congenital membranous cataract. J Ophthalmol. 2017;2017. https://doi.org/10.1155/2017/2370969.

44. Xiang D, Chen L, Hu L, Song S, Xie W, Long J. Image features of lens opacity in pediatric cataracts using ultrasound biomicroscopy. J AAPOS. 2016;20:519-22.e4. https://doi.org/10.1016/j.jaapos. 2016.08.014.

45. El Shakankiri NM, Bayoumi NH, Abdallah AH, El Sahn MMF. Role of ultrasound and biomicroscopy in evaluation of anterior segment anatomy in congenital and developmental cataract cases. J Cataract Refract Surg. 2009;35:1893-905. https://doi.org/10. 1016/j.jcrs.2009.07.007.

46. Elfiky M, Saad H, Elseht R, Selima A. Role of ultrasound biomicroscopy in the planning for secondary implantation of intra ocular lens in aphakia. Int Ophthalmol. 2016;36:391-400. https:// doi.org/10.1007/s10792-015-0141-z.

47. You C, Wu X, Ying L, Xie L. Ultrasound biomicroscopy imaging of sclerotomy in children with cataract undergoing 25-gauge sutureless pars plana anterior vitrectomy. Eur J Ophthalmol. 2010;20:1053-8. https://doi.org/10.1177/112067211002000605.

48. Nishijima K, Takahashi K, Yamakawa R. Ultrasound biomicroscopy of the anterior segment after congenital cataract surgery. Am J Ophthalmol. 2000;130:483-9. https://doi.org/10.1016/ s0002-9394(00)00524-9.

49. Özdal MP, Mansour M, Deschênes J. Ultrasound biomicroscopic evaluation of the traumatized eyes. Eye 2003;17:467-72. https:// doi.org/10.1038/sj.eye.6700382.

50. Moura MFde, Hayashi I, Rocha DM, Allemann N. Evaluation of anterior segment foreign bodies with ultrasound biomicroscopy. Arq Bras Oftalmol. 2012;75:122-5. https://doi.org/10.1590/ s0004-27492012000200010.

51. Mohammadi SF, Zandian M, Fakhraie G, et al. Ultrasound biomicroscopy findings in fireworks-related blunt eye injuries. Eur J Ophthalmol. 2012;22:342-8. https://doi.org/10.5301/ejo.5000017.

52. Lin Y, Liang X, Liu X, et al. Prognostic factors and visual outcome for fireworks-related burns during spring festival in South China. J Burn Care Res. 2012;33:e108-13. https://doi.org/10. 1097/BCR.0b013e3182335998.
53. Zhou SY, Wang CX, Cai XY, Huang D, Liu YZ. Optical coherence tomography and ultrasound biomicroscopy imaging of opaque corneas. Cornea. 2013;32:e25-30. https://doi.org/10.1097/ ICO.0b013e318261eb2b.

54. Nischal KK, Naor J, Jay V, MacKeen LD, Rootman DS. Clinicopathological correlation of congenital corneal opacification using ultrasound biomicroscopy. Br J Ophthalmol. 2002;86:62-9. https://doi.org/10.1136/bjo.86.1.62.

55. Rezende RA, Uchoa UBC, Uchoa R, Rapuano CJ, Laibson PR, Cohen EJ. Congenital corneal opacities in a cornea referral practice. Cornea. 2004;23:565-70. https://doi.org/10.1097/01.ico. 0000126317.90271.d8.

56. Darusman KR, Wong IB. Ultrasound biomicroscopy imaging in pediatric patients. J Am Assoc Pediatr Ophthalmol Strabismus. 2012;16:e30. https://doi.org/10.1016/j.jaapos.2011.12.116.

57. Chen WS, Xiang DM, Hu LX. Ultrasound biomicroscopy detects Peters' Anomaly and Rieger's Anomaly in Infants. J Ophthalmol. 2020;2020. https://doi.org/10.1155/2020/8346981.

58. Miao S, Lin Q, Liu Y, Song YW, Zhang YN, Pan ZQ. Clinicopathologic features and treatment characteristics of congenital corneal opacity infants and children aged 3 years or less: a retrospective single institution analysis. Med Princ Pract. 2020;29:18-24. https://doi.org/10.1159/000501763.

59. Mireskandari K, Ali A, Elbaz U, Strungaru H. Characterizing the phenotypic spectrum of Peters anomaly: from mild to severe disease. Investig Ophthalmol Vis Sci. 2015;56:1553.

60. Nakagawa T, Maeda N, Okazaki N, Hori Y, Nishida K, Tano Y. Ultrasound biomicroscopic examination of acute hydrops in patients with keratoconus. Am J Ophthalmol. 2006;141:11341136. https://doi.org/10.1016/j.ajo.2005.12.043.

61. Sharma N, Mannan R, Jhanji V, et al. Ultrasound biomicroscopyguided assessment of acute corneal hydrops. Ophthalmology. 2011;118:2166-71. https://doi.org/10.1016/j.ophtha.2011.03.040.

62. Miranda D, Sartori M, Francesconi C, Allemann N, Ferrara P, Campos M. Ferrara intrastromal corneal ring segments for severe keratoconus. J Refract Surg. 2003;19:645-53. https://doi.org/10. 3928/1081-597X-20031101-06.

63. Harding SA, Nischal KK, Upponi-Patil A, Fowler DJ. Indications and outcomes of deep anterior lamellar keratoplasty in children. Ophthalmology. 2010;117:2191-5. https://doi.org/10.1016/j. ophtha.2010.03.025.

64. Maripudi S, Byrd J, Qureshi A, et al. Pediatric Corneal Structural Development During Childhood Characterized by Ultrasound Biomicroscopy. J Pediatr Ophthalmol Strabismus. 2020;57:238245. https://doi.org/10.3928/01913913-20200506-01.

65. Emery J, Ho D, Mackeen L, Héon E, Bissonnette B. Pupillary reflex dilation and skin temperature to sensory level during combined general and caudal anesthesia in children. Paediatr Anaesth. 2004;14:768-73. https://doi.org/10.1111/j.1460-9592. 2004.01308.x.

66. Dai S, Kraft SP, Smith DR, Buncic JR. Ultrasound biomicroscopy in strabismus reoperations. J AAPOS. 2006;10:202-5. https://doi. org/10.1016/j.jaapos.2006.01.209.

67. Khan HA, Smith DR, Kraft SP. Localising rectus muscle insertions using high frequency wide-field ultrasound biomicroscopy. Br J Ophthalmol. 2012;96:683-7. https://doi.org/10.1136/ bjophthalmol-2011-300960.

68. Mirmohammadsadeghi A, Manuchehri V, Akbari MR. The accuracy of wide-field ultrasound biomicroscopy in localizing extraocular rectus muscle insertions in strabismus reoperations. $\mathbf{J}$ AAPOS. 2017;21:463-6.e1. https://doi.org/10.1016/j.jaapos. 2017.07.209.

69. Thakur N, Singh R, Kaur S, Kumar A, Phuljhele S, Sukhija J. Ultrasound biomicroscopy in strabismus surgery: Efficacy in postoperative assessment of horizontal muscle insertions. 
Strabismus. 2015;23:73-9. https://doi.org/10.3109/09273972. 2015.1025987.

70. Solarte CE, Smith DR, Buncic JR, Tehrani NN, Kraft SP. Evaluation of vertical rectus muscles using ultrasound biomicroscopy. J AAPOS. 2008;12:128-31. https://doi.org/10.1016/j.jaapos.2007. 06.019.

71. Bajaj MS, Aalok L, Gupta V, Sen S, Pushker N, Chandra M. Ultrasound biomicroscopic appearances of eyelid lesions at 50 MHz. J Clin Ultrasound. 2007;35:424-9. https://doi.org/10.1002/ jcu.20368.

72. Surve A, Meel R, Pushker N, Bajaj M. Ultrasound biomicroscopy image patterns in normal upper eyelid and congenital ptosis in the Indian population. Indian J Ophthalmol. 2018;66:383-8. https:// doi.org/10.4103/ijo.IJO_915_17.

73. Zhang YS, Zhou Q, Zhang J, et al. Local retro-orbicularis oculus fat (ROOF) resection in upper blepharoplasty: A retrospective evaluation study of 65 bilateral upper blepharoplasties. J Plast Reconstr Aesthet Surg. 2019;72:1373-8. https://doi.org/10.1016/j. bjps.2019.04.010.

74. El-Zawahry MBM, Abdel El-Hameed El-Cheweikh HM, AbdEl-Rahman Ramadan S, Ahmed Bassiouny D, Mohamed Fawzy M. Ultrasound biomicroscopy in the diagnosis of skin diseases. Eur J Dermatol. 2007;17:469-75. https://doi.org/10.1684/ejd. 2007.0261.

75. Al-Faky YH. Anatomical utility of ultrasound biomicroscopy in the lacrimal drainage system. Br J Ophthalmol. 2011;95:1446-50. https://doi.org/10.1136/bjo.2010.195479.

76. Al-Faky YH. Physiological utility of ultrasound biomicroscopy in the lacrimal drainage system. Br J Ophthalmol. 2013;97:1325-9. https://doi.org/10.1136/bjophthalmol-2013-303662.

77. Sharma A, Ali A, Henderson RH, Patel CK, VandenHoven C, Lam WC. Accuracy of scleral transillumination techniques to identify infant ciliary body for sclerostomy and intravitreal injections. Clin Exp Ophthalmol. 2019;47:478-83. https://doi.org/ 10.1111/ceo.13442.

78. Li Z, Li Y, Huang X, et al. Quantitative analysis of rhegmatogenous retinal detachment associated with choroidal detachment in cinese using UBM. Retina. 2012;32:2020-5. https://doi.org/10. 1097/IAE.0b013e3182561f7c.

79. Nakagawa N, Kinoshita I, Hayashi H, Oshima K. Biometry of the ciliary body in premature eyes using ultrasound biomicroscope. Jpn J Ophthalmol. 1996;50:1145-8.

80. Kobayashi H, Kiryu J, Kobayashi K, Kondo T. Ultrasound biomicroscopic measurement of anterior chamber angle in premature infants. Br J Ophthalmol. 1997;81:460-4. https://doi.org/10.1136/ bjo.81.6.460.

81. Anaya-Olvera A, Martinez-Castellanos MA, Lechuga R, Mayorquin-Ruiz M. Ultrasound biomicroscopy of anterior segment in premature infants. Invest. Ophthalmol. Vis. Sci. 2014;55:4867.

82. Ludwig K, Wegscheider E, Hoops JP, Kampik A. In vivo imaging of the human zonular apparatus with high-resolution ultrasound biomicroscopy. Graefes Arch Clin Exp Ophthalmol. 1999;237:361-71. https://doi.org/10.1007/s004170050245.

83. Bacskulin A, Martin H, Kundt G, Terwee T, Guthoff R. Analyse der Dynamik des Ziliarmuskels während der Akkommodation [Analysis of the dynamics of the ciliary muscle during accommodation]. Ophthalmologe. 2000;97:855-9. https://doi.org/10. 1007/s003470070008.

84. Tsuchiya AK, Tanaka K, Sakurada I, Oba S, Mizuki N. Ultrasound biomicroscopic measurement of anterior chamber biometry between before and after pupil dilation in children. Eur $\mathrm{J}$ Ophthalmol. 2008;18:532-9. https://doi.org/10.1177/112067210801800405.
85. Kobayashi H, Kobayashi K. Quantitative comparison of ZeissHumphrey model 840 and Rion UX-02 systems of ultrasound biomicroscopy. Graefe's Arch Clin Exp Ophthalmol. 1999;237:381-6. https://doi.org/10.1007/s004170050248.

86. Kobayashi H, Ono H, Kiryu J, Kobayashi K, Kondo T. Ultrasound biomicroscopic measurement of development of anterior chamber angle. Br J Ophthalmol. 1999;83:559-62. https://doi.org/ 10.1136/bjo.83.5.559.

87. Le KH, Stoleru G, Jaafar MS, et al. Normal ciliary body growth using anterior segment ultrasound biomicroscopy. J Am Assoc Pediatr Ophthalmol Strabismus. 2017;21:e24. https://doi.org/10. 1016/j.jaapos.2017.07.080.

88. Snook KA, Zhao J-Z, Alves CHF, et al. Design, fabrication, and evaluation of high frequency, single-element transducers incorporating different materials. IEEE Trans Ultrason Ferroelectr Freq Control. 2002;49:169-76. https://doi.org/10.1109/58.985701.

89. Ritter TA, Shrout TR, Tutwiler R, Shung KK. A 30-MHz piezocomposite ultrasound array for medical imaging applications. IEEE Trans Ultrason Ferroelectr Freq Control. 2002;49:217-30. https://doi.org/10.1109/58.985706.

90. Liu C, Djuth FT, Zhou Q, Shung KK. Micromachining techniques in developing high-frequency piezoelectric composite ultrasonic array transducers. IEEE Trans Ultrason Ferroelectr Freq Control. 2013;60:2615-25. https://doi.org/10.1109/TUFFC.2013.2860.

91. Cannata JM, Williams JA, Zhang L, Hu C-H, Shung KK. A highfrequency linear ultrasonic array utilizing an interdigitally bonded 22 piezo-composite. IEEE Trans Ultrason Ferroelectr Freq Control. 2011;58:2202-12. https://doi.org/10.1109/TUFFC.2011.2070.

92. Liu C, Zhou Q, Djuth FT, Shung KK. High-frequency (>50 MHz) medical ultrasound linear arrays fabricated from micromachined bulk PZT materials. IEEE Trans Ultrason Ferroelectr Freq Control. 2012;59:315-8. https://doi.org/10.1109/TUFFC.2012.2193.

93. Sun Y, Xie H, Liu J, et al. In vivo validation of a bimodal technique combining time-resolved fluorescence spectroscopy and ultrasonic backscatter microscopy for diagnosis of oral carcinoma. J Biomed Opt. 2012;17:116003. https://doi.org/10.1117/1.JBO. 17.11.116003.

94. Ramasubramanian V, Glasser A. Prediction of accommodative optical response in prepresbyopic subjects using ultrasound biomicroscopy. J Cataract Refract Surg. 2015;41:964-80. https://doi. org/10.1016/j.jcrs.2014.12.049.

95. Qureshi A, Chen H, Saeedi O, et al. Anterior segment ultrasound biomicroscopy image analysis using ImageJ software: Intra-observer repeatability and inter-observer agreement. Int Ophthalmol. 2019;39:829-37. https://doi.org/10.1007/s10792-018-0882-6.

96. Alexander JL, Maripudi S, Kannan K, Kaleem M, Saeedi OJ, Levin MR, Madigan WP. Assessment of a novel open access tool for automated evaluation of anterior segment structures in patients with and without glaucoma. Presented to the American Academy of Ophthalmology, Chicago, IL, USA. October, 2018.

97. Shi G, Jiang Z, Deng G, et al. Automatic classification of anterior chamber angle using ultrasound biomicroscopy and deep learning. Transl Vis Sci Technol. 2019;8:25. https://doi. org/10.1167/tvst.8.4.25.

98. Nahum Y, Galor O, Atar M, Bahar I, Livny E. Real-time intraoperative ultrasound biomicroscopy for determining graft orientation during Descemet's membrane endothelial keratoplasty. Acta Ophthalmol. 2020. https://doi.org/10.1111/aos.14515.

99. Zhu X-J, Zhang K-K, He W-W, Sun X-H, Meng F-R, Lu Y. Diagnosis of pupillary block glaucoma after removal of congenital cataracts with intraoperative ultrasound biomicroscopy: a case report. BMC Ophthalmol. 2016;16:58. https://doi.org/10.1186/ s12886-016-0238-9. 